\title{
Development of Disposable Single-Use Biosensor for Fructosyl Valine and Glycated Hemoglobin A1c
}

\author{
Sean Liu*, Jessica Leng, Theonalyn C. Aquino \\ Department of Chemistry and Biochemistry, California State Polytechnic University, Pomona, CA, USA \\ Email: *xcliu@cpp.edu
}

How to cite this paper: Liu, S., Leng, J. and Aquino, T.C. (2019) Development of Disposable Single-Use Biosensor for Fructosyl Valine and Glycated Hemoglobin Alc. Journal of Sensor Technology, 9, 45-53. https://doi.org/10.4236/jst.2019.94005

Received: September 6, 2019

Accepted: November 19, 2019

Published: November 22, 2019

Copyright $\odot 2019$ by author(s) and Scientific Research Publishing Inc. This work is licensed under the Creative Commons Attribution International License (CC BY 4.0).

http://creativecommons.org/licenses/by/4.0/

\section{(c) (i) Open Access}

\begin{abstract}
A novel amperometric biosensor prototype was fabricated using screen printing technique. The disposable single-use strips were made from conductive carbon ink and modified with fructosyl amino acid oxidase. The electrodes and conducting paths were made solely with carbon ink and characterized by conductivity and cyclic voltammetry. The biosensor showed high current output, large linearity, and effectiveness for fructosyl valine as well as human blood samples. Amperometric studies were carried out using both fructosyl valine and human blood samples. With $5 \mathrm{uL}$ sample volume, the biosensor showed strong amperometric response with good linearity for a wide range (0 to $8 \mathrm{mM}$ ). Diabetic and healthy blood samples showed sufficient difference in their amperometric responses that correlate well with their different hemoglobin A1c levels. These results demonstrate the feasibility of using this type of inexpensive single-use biosensor strips as the basis for determining hemoglobin Alc levels for diabetic patients.
\end{abstract}

\section{Keywords}

Screen Printed Biosensor, Glycated Hemoglobin A1c, Diabetes

\section{Introduction}

Hemoglobin $(\mathrm{Hb})$ is the oxygen-transport protein and hemoglobin $\mathrm{A} 1$ (HbA1) is the most abundant hemoglobin component in human erythrocytes. Upon glycosylation, HbA1 will form glycated hemoglobin A1c (HbAlc or A1c) by a non-enzymatic glycosylation process. HbAlc level indicates the mean glycemic control during the preceding 120 days [1]. Diabetes Control and Complications 
Trial (DCCT) has established the relationship between HbAlc level and the risks for development and progression of chronic complications of diabetes. Measurement of HbAlc is very important in the diagnosis and management of patients with diabetes mellitus [2]. A1c is also a precursor for advanced glycation end-products (AGE). In addition to diabetes, AGEs have been implicated in Alzheimer's Disease [3], cardiovascular disease [4], and stroke [5]. Moreover, higher A1c levels pose an elevated risk of cardiovascular disease to even nondiabetic adults [6].

In 2010, the American Diabetes Association (ADA) included the A1c test among tests for detecting diabetes and pre-diabetes, a condition in which blood glucose levels are high but not high enough to be diagnosed as diabetes. People with pre-diabetes are at an increased risk of developing diabetes. The ADA announced this change in its Standards of Medical Care in Diabetes-2010 [7]. Since then, A1c assays have been accepted as diagnostic and screening tools. However, the current methods for quantifying A1c are neither convenient nor economical. Typically, patients need to go to a diagnostic site to have blood drawn; the blood samples are sent to a centralized location for analysis. The results won't be available until a few days later. Clinical labs use a number of different analytical systems to determine A1c levels that include boronate affinity chromatography, ionic exchange HPLC, and immunoassay [8] [9]. Expensive instruments are employed in those assays. It is thus highly desirable to have a method that is fast, inexpensive and can be used at many different clinical sites as well as patients' home. In this paper we report the development of new single-use strips for A1c determination.

The method is based on the catalytic property of fructosyl amino acid oxidase (FAO) [10] [11] [12]. Glycated hemoglobin A1c is a hemoglobin molecule in which the N-terminal valine residue of the beta subunit has been nonenzymatically modified by blood glucose [13] [14]. The International Federation of Clinical Chemistry and Laboratory Medicine (IFCC) established an international standard for the measurement of $\mathrm{HbAlc}$ based on the determination of the fructosyl hexapeptide (fVHLTPE) that is liberated by the digestion of HbAlc by endoproteinase Glu-C [15]. Fructosyl amino acid oxidase catalyzes the oxidation of fructosyl valine (FV) into D-glucosone, valine and the concurrent production of hydrogen peroxide which can be determined electrochemically on an electrode [16]. Fructosyl valine needs to be released from A1c first through proteolysis via the action of proteases. The described method consists of the following three steps:

$$
\begin{gathered}
\mathrm{HbAlc} \stackrel{\text { endoproteinase Glu-C }}{\longrightarrow} \text { fructosyl-Val-His-Leu-Thr-Pro-Glu(fVHLTPE) } \\
\mathrm{fVHLTPE} \stackrel{\text { protease }}{\longrightarrow} \text { fructosyl-Valine + oligopeptides + amino acids }
\end{gathered}
$$

$$
\text { fructosyl-Valine }+\mathrm{O}_{2}+\mathrm{H}_{2} \mathrm{O} \stackrel{\text { FAO }}{\longrightarrow} \mathrm{L} \text {-valine }+ \text { D-glucosone }+\mathrm{H}_{2} \mathrm{O}_{2}
$$

Fructosyl amino acid oxidase has been reported in the literature for determi- 
nation of glycated hemoglobin using electrochemical method. For example, Chawla and Pundir reported using FAO modified gold electrode for quantifying HbA1c [17]. However, it wasn't single use screen printed electrode (SPE) such as glucose strips. Fan et al reported FAO modified iridium electrode for quantifying HbAlc that was single-use SPE, however, there was no blood sample tested on the iridium SPE [18]. In this paper, we report our work on single-use carbon SPE that was modified with FAO. The SPEs have been tested on both fructosyl-valine and blood samples from healthy and diabetic subjects.

\section{Material and Methods}

\subsection{Material and Apparatus}

Enzymes including FAO, proteases were from Jinruida Biotech Co. (Changsha, China), Melinex polyester films were from TEKRA, Inc. (New Berlin, WI, USA), all other chemicals were of analytical grade. Blood samples from healthy and diabetic subjects were collected from Hospital of Liuyang (Liuyang, China). Treated blood samples were concentrated by 4.5 fold using lyophilization before use. All solutions were prepared using deionized water. Screen printed electrodes were fabricated using an ATMA AT-60PD digital electric flat screen printer (New Taipei City, Taiwan). Carbon and insulating inks were from Guilin Pinzhen Biotech Co. (Guilin, China). These inks were used for making commercial glucose strips for glucometers by several companies in Asia. Electrochemical studies were performed using a Wavenow potentiostat (Pine Research Instrumentation, Durham, NC, USA). Comparative assays were performed on an automatic biochemistry analyzer Mindray BS200 (Shenzhen, China).

\subsection{Methods}

Synthesis of fructosyl valine:

Fructosyl valine was synthesized in house using a published method [19] as it was not commercially available. L-valine $(1.88 \mathrm{~g}, 16 \mathrm{mmol})$ was added to $80 \mathrm{~mL}$ of a mixture of pyridine and acetic acid in 1:1 ratio. After stirring at room temperature for 30 minutes, glucose $(4.0 \mathrm{~g}, 22 \mathrm{mmol})$ was added. The mixture was purged with Ar for 10 minutes and then gently stirred for 4 days at room temperature. After evaporation of solvent, the crude product was re-crystallized in methanol which yielded a pale yellow solid.

Fabrication of enzyme screen printed electrodes:

Dimensions of the screen printed electrodes are shown in Figure 1. Screen printed electrodes were fabricated using an ATMA semi-automatic screen printer on Melinex polyester substrates. There were 30 electrodes on each sheet $(5 \times$ 7 in). The three electrodes were first printed using graphite-based ink, and dried at $110^{\circ} \mathrm{C}$ for $15 \mathrm{~min}$. Then the insulating layer was printed using the insulting ink and dried at $105^{\circ} \mathrm{C}$ for $10 \mathrm{~min}$. The enzyme mixture (10 ul) was drop coated onto the electrodes and air dried in fume hood. Unused electrodes were store in refrigerator. 


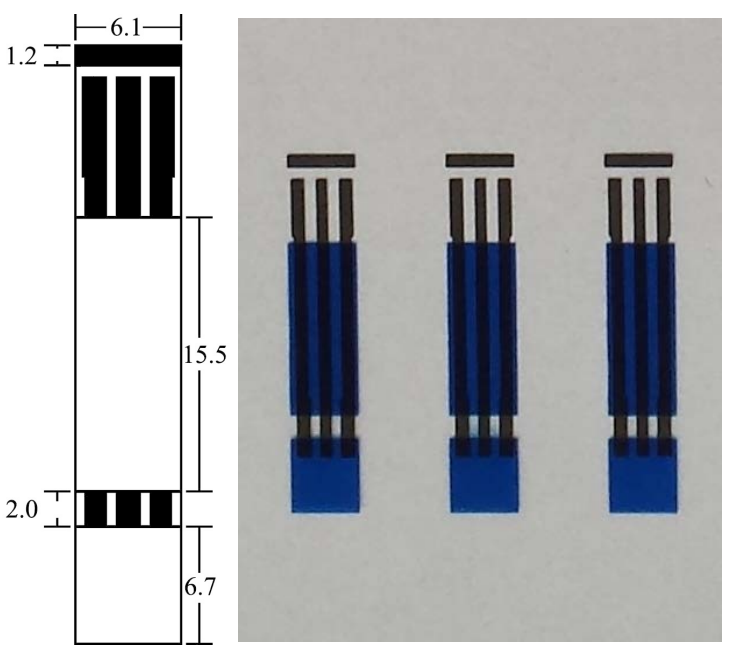

(a)

(b)

Figure 1. Dimension of a screen printed electrode in millimeters (a), and an image of three screen printed electrodes (b). The insulator is shown in blue.

Cyclic voltammetry was carried out using a Wavenow potentiostat with AfterMath software package with the following parameters: upper potential: 650 $\mathrm{mv}$, lower potential: $100 \mathrm{mv}$, final potential: $0 \mathrm{mv}$, initial direction: rising, scan rates: $200 \mathrm{mV} / \mathrm{s}$.

Amperometric measurement was carried out using a Wavenow potentiostat with AfterMath software package. Working potential was set at $-900 \mathrm{mV}$ relative to reference electrode.

\section{Results and Discussion}

\subsection{Cyclic Voltammetric Performance of Screen Printed Electrodes}

After drying the SPEs, the thickness of carbon tracks are measured to be fairly uniform in about 10 micron. The resistance of each carbon track was also measured. Results show similar resistance, roughly 1.5 kilohms.

To evaluate the charge transfer properties of our fabricated of SPEs, cyclic voltammetry was employed using the ferri/ferrocyanide redox couples. Cyclic voltammograms were recorded in three different concentrations of $\mathrm{K}_{3} \mathrm{Fe}(\mathrm{CN})_{6} / \mathrm{K}_{4} \mathrm{Fe}(\mathrm{CN})_{6}\left(1: 1\right.$ ratio in $\left.1 \mathrm{M} \mathrm{KNO}_{3}\right)$ as shown in Figure 2. As a comparison, one type of commercial SPEs used as blood glucose strips was also studied. The electrodes on these glucose strips were screen printed with conductive carbon ink. As shown in Figure 2, our self-made SPE and the commercial SPE showed similar (though far from ideal) behavior on cyclic voltammograms. The poor reversibility was attributed to partly by the fact that the conducting paths were made solely with carbon ink. The effect of increasing concentration on the appearance of the voltammograms, dictated by Randles-Sevcik equation, can be seen in the figure. 


\subsection{Amperometric Study Using Fructosyl Valine}

Amperometric study using fructosyl valine was carried out first to validate the testing approach. Various concentrations of FV (0 to $8 \mathrm{mM})$ were prepared in phosphate buffer saline (PBS, pH 7.0) and tested using $5 \mathrm{uL}$ as sample volume. Figure 3 shows the amperometric responses which have a well-behaved pattern. The current reading increases proportionally as the FV concentration increases, which is defined by the Michaelis-Menten equation at lower substrate concentrations. The current reading is about one order of magnitude higher than previously reported [18], and is similar to the current level generated by commercial glucose strips. This is much more favorable for making a small portable biosensor for A1c or, even better, integrate it into an existing glucometer. Figure 4 shows the calibration curve constructed using amperometric responses at $60 \mathrm{~s}$. One can see a good linearity over a large range which covers both healthy and diabetic A1c levels [20]. Moreover, the $60 \mathrm{~s}$ time frame is also a favorable factor for making a practical sensing device.



(a)

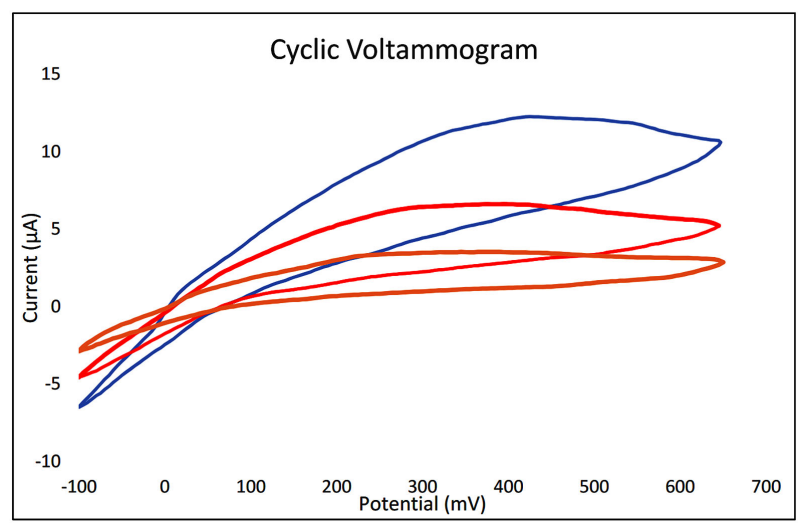

(b)

Figure 2. Cyclic voltammograms of (a) self-made SPE, and (b) commercial SPE used in glucometer Cyclic voltammetry was carried out using a Wavenow potentiostat with After Math software package with the following parameters: upper potential: $650 \mathrm{mv}$, lower potential: $100 \mathrm{mv}$, final potential: $0 \mathrm{mv}$, initial direction: rising, scan rates: $200 \mathrm{mV} / \mathrm{s}$; concentrations of $\mathrm{K}_{3} \mathrm{Fe}(\mathrm{CN})_{6} / \mathrm{K}_{4} \mathrm{Fe}(\mathrm{CN})_{6}: 1.0,2.0$, and $4.0 \mathrm{mM}$ (lower to upper voltammograms). 


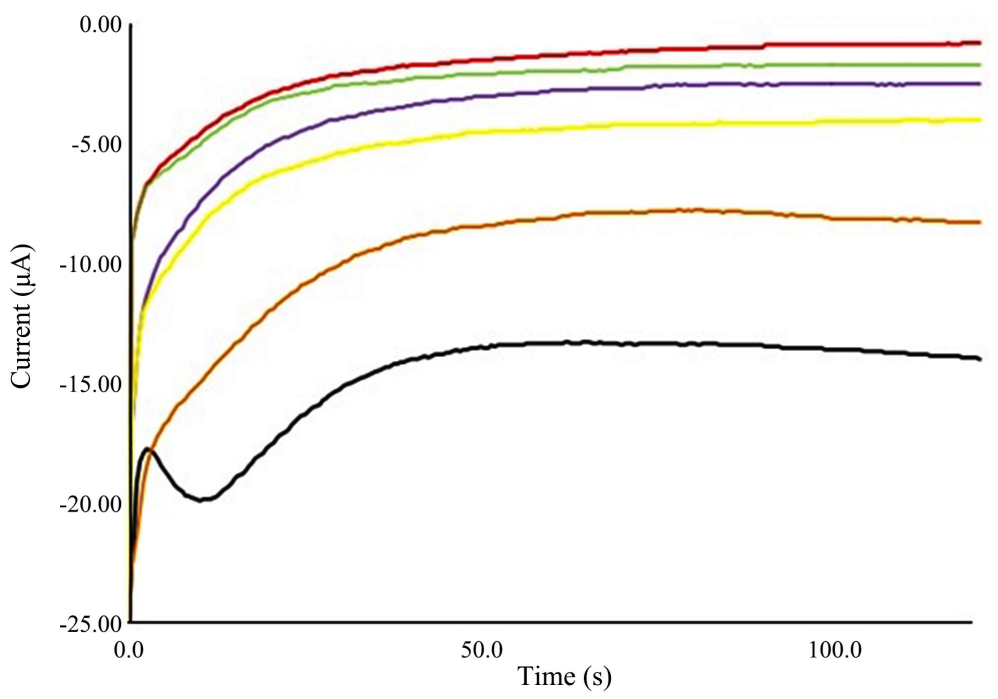

Figure 3. Chronoamperometric response of fructosyl valine. Amperometric measurement was carried out using a Wavenow potentiostat with AfterMath software package. Working potential was set at $-900 \mathrm{mV}$ relative to reference electrode, $\mathrm{FV}$ concentrations are $0,0.5,1.0,2.0,4.0$, and $8.0 \mathrm{mM}$ (upper to lower curves).

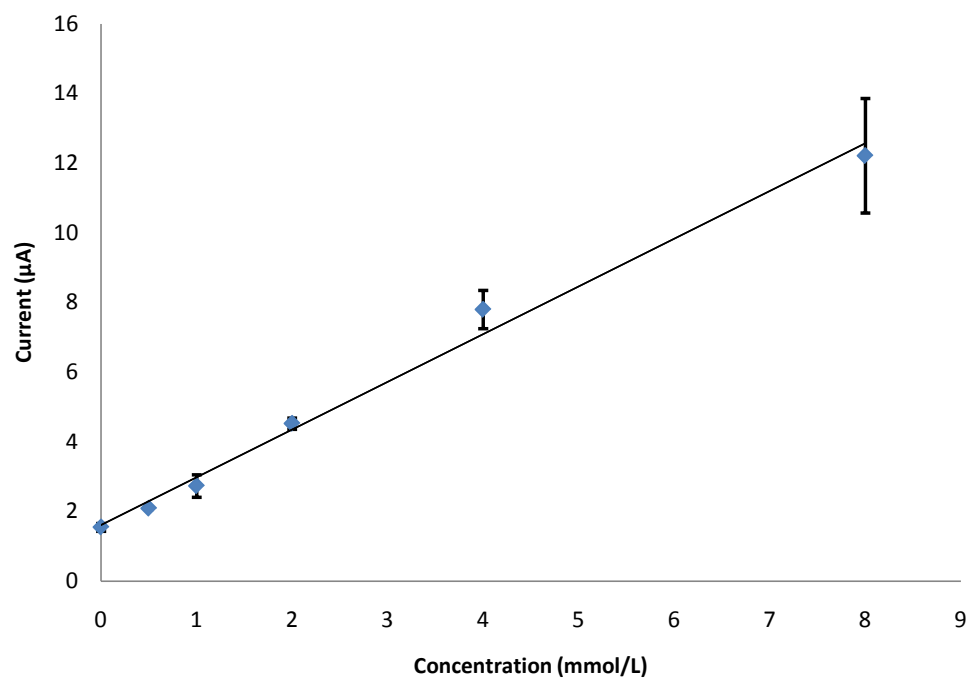

Figure 4. Calibration curve of fructosyl valine using amperometric responses at $60 \mathrm{~s}$ with fructosyl valine concentrations $0,0.5,1.0,2.0,4.0$, and $8.0 \mathrm{mM}$.

\subsection{Amperometric Study Using Human Bloods}

Blood samples from both healthy and diabetic subjects were then tested using our enzyme-modified SPEs. Blood samples were treated with proteases first and $5 \mathrm{uL}$ was used as testing volume. Figure 5 shows the amperometric responses from both samples. One can see the diabetic sample has a higher current than the healthy sample. The difference represents a $1.0 \mathrm{mM} \mathrm{A1c}$ higher in the diabetic sample. For comparison, both samples were also analyzed on an automatic biochemistry analyzer for total hemoglobin and A1c levels. A1c levels were $5.4 \%$ for the healthy subject and $12.1 \%$ for the diabetic subject. This shows a 


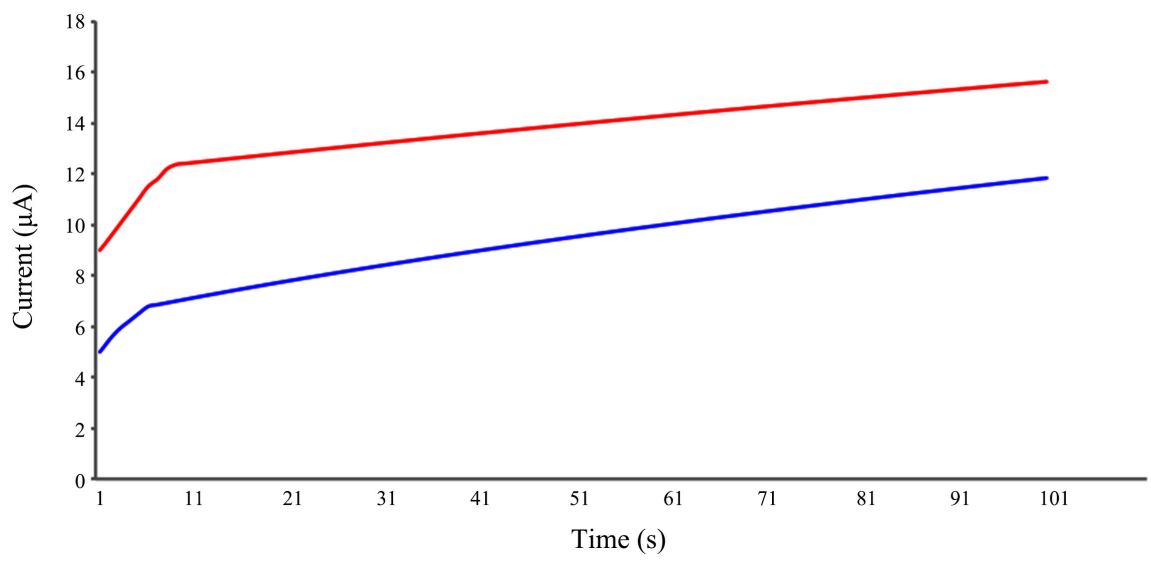

Figure 5. Chronoamperometric response of blood samples from healthy and diabetic subjects. Lower curve: diabetic subject, upper curve: healthy subject.

6.7\% higher A1c level in the diabetic subject. The $1.0 \mathrm{mM} \mathrm{A1c}$ increase measured using our SPE corresponds to a 7.5\% increase which agrees reasonably well with the $6.7 \%$ determined by the automatic biochemistry analyzer. These results demonstrate the feasibility of using the SPE as the basis for determining A1c levels for diabetic patients. More studies are underway for optimization of the method.

\section{Conclusion}

In summary, a novel amperometric biosensor prototype was fabricated using screen printing technique. The disposable single-use strips were made from conductive carbon ink and modified with fructosyl amino acid oxidase. The biosensor showed high current output, large linearity, and effectiveness for fructosyl valine as well as human blood samples.

\section{Conflicts of Interest}

The authors declare no conflicts of interest regarding the publication of this paper.

\section{References}

[1] Rochman, H. (1980) Hemoglobin A1c and Diabetes Mellitus. Annals of Clinical \& Laboratory Science, 10, 111-115.

[2] Sacks, D.B., Bruns, D.E., Goldstein, D.E., Maclaren, N.K., McDonald, J.M. and Parrott, M. (2002) Guidelines and Recommendations for Laboratory Analysis in the Diagnosis and Management of Diabetes Mellitus. Clinical Chemistry, 48, 436-472.

[3] Srikanth, V., Maczurek, A., Phan, T., Steele, M., Westcott, B., Juskiw, D. and Münch, G. (2011) Advanced Glycation Endproducts and Their Receptor RAGE in Alzheimer's Disease. Neurobiology of Aging, 32, 763-777. https://doi.org/10.1016/j.neurobiolaging.2009.04.016

[4] Simm, A., Wagner, J., Gursinsky, T., Nass, N., Friedrich, I., Schinzel, R., Czeslik, E., Silber, R. and Scheubel, R. (2007) Advanced Glycation Endproducts: A Biomarker for Age as an Outcome Predictor after Cardiac Surgery? Experimental Gerontology, 
42, 668-675. https://doi.org/10.1016/j.exger.2007.03.006

[5] Zimmerman, G.A., Meistrell, M., Bloom, O., Cockroft, K.M., Bianchi, M., Risucci, D., Broome, J., Farmer, P., Cerami, A. and Vlassara, H. (1995) Neurotoxicity of Advanced Glycation Endproducts during Focal Stroke and Neuroprotective Effects of Aminoguanidine. Proceedings of the National Academy of Sciences, 92, 3744-3748. https://doi.org/10.1073/pnas.92.9.3744

[6] Selvin, E., Steffes, M.W., Zhu, H., Matsushita, K., Wagenknecht, L., Pankow, J., Coresh, J. and Brancati, F.L. (2010) Glycated Hemoglobin, Diabetes, and Cardiovascular Risk in Nondiabetic Adults. New England Journal of Medicine, 362, 800-811. https://doi.org/10.1056/NEJMoa0908359

[7] Association, A.D. (2010) Standards of Medical Care in Diabetes 2010. Diabetes Care, 33, S11-S61. https://doi.org/10.2337/dc10-S011

[8] Liu, X.-C. (2006) Boronic Acids as Ligands for Affinity Chromatography. Chinese Journal of Chromatography, 24, 73-80. https://doi.org/10.1016/S1872-2059(06)60004-7

[9] Ozcelik, F., Yiginer, O., Serdar, M.A., Kurt, I., Oztosun, M., Arslan, E. and Orhun, A. (2010) Comparison of Three Methods for Measurement of HbA1c. Turkish Journal of Biochemistry Turk Biyokimya Dergisi, 35, 344-349.

[10] Ferri, S., Miyamoto, Y., Sakaguchi-Mikami, A., Tsugawa, W. and Sode, K. (2013) Engineering Fructosyl Peptide Oxidase to Improve Activity toward the Fructosyl Hexapeptide Standard for HbA1c Measurement. Molecular Biotechnology, 54, 939-943. https://doi.org/10.1007/s12033-012-9644-2

[11] Kim, S., Miura, S., Ferri, S., Tsugawa, W. and Sode, K. (2009) Cumulative Effect of Amino Acid Substitution for the Development of Fructosyl Valine-Specific Fructosyl Amine Oxidase. Enzyme and Microbial Technology, 44, 52-56. https://doi.org/10.1016/j.enzmictec.2008.09.001

[12] Lin, Z. and Zheng, J. (2010) Occurrence, Characteristics, and Applications of Fructosyl Amine Oxidases (Amadoriases). Applied Microbiology and Biotechnology, 86, 1613-1619. https://doi.org/10.1007/s00253-010-2523-5

[13] Koenig, R.J., Blobstein, S.H. and Cerami, A. (1977) Structure of Carbohydrate of Hemoglobin AIc. Journal of Biological Chemistry, 252, 2992-2997.

[14] Stevens, V.J., Vlassara, H., Abati, A. and Cerami, A. (1977) Nonenzymatic Glycosylation of Hemoglobin. Journal of Biological Chemistry, 252, 2998-3002.

[15] Jeppsson, J.-O., Kobold, U., Barr, J., Finke, A., Hoelzel, W., Hoshino, T., Miedema, K., Mosca, A., Mauri, P. and Paroni, R. (2002) Approved IFCC Reference Method for the Measurement of HbAlc in Human Blood. Clinical Chemistry and Laboratory Medicine, 40, 78-89. https://doi.org/10.1515/CCLM.2002.016

[16] Ferri, S., Kim, S., Tsugawa, W. and Sode, K. (2009) Review of Fructosyl Amino Acid Oxidase Engineering Research: A Glimpse into the Future of Hemoglobin A1c Biosensing. Journal of Diabetes Science and Technology, 3, 585-592. https://doi.org/10.1177/193229680900300324

[17] Chawla, S. and Pundir, C.S. (2011) An Electrochemical Biosensor for Fructosyl Valine for Glycosylated Hemoglobin Detection Based on Core-Shell Magnetic Bionanoparticles Modified Gold Electrode. Biosensors and Bioelectronics, 26, 3438-3443. https://doi.org/10.1016/j.bios.2011.01.021

[18] Fang, L., Li, W., Zhou, Y. and Liu, C.-C. (2009) A Single-Use, Disposable Iridium-Modified Electrochemical Biosensor for Fructosyl Valine for the Glycoslated Hemoglobin Detection. Sensors and Actuators B: Chemical, 137, 235-238. https://doi.org/10.1016/j.snb.2008.09.045 
[19] Rajkumar, R., Warsinke, A., Möhwald, H., Scheller, F.W. and Katterle, M. (2007) Development of Fructosyl Valine Binding Polymers by Covalent Imprinting. Biosensors and Bioelectronics, 22, 3318-3325. https://doi.org/10.1016/j.bios.2007.03.001

[20] Ogawa, K., Stöllner, D., Scheller, F., Warsinke, A., Ishimura, F., Tsugawa, W., Ferri, S. and Sode, K. (2002) Development of a Flow-Injection Analysis (FIA) Enzyme Sensor for Fructosyl Amine Monitoring. Analytical and Bioanalytical Chemistry, 373, 211-214. https://doi.org/10.1007/s00216-002-1319-6 